\title{
Compact Wideband Microstrip Patch Antenna based on High Impedance Surface
}

\author{
Suman Nelaturi \\ Department of Electronics and Communication Engineering \\ National Institute of Technology Warangal \\ Warangal, India \\ nelaturi.suman4@gmail.com
}

\author{
N. V. S. N. Sarma \\ Department of Electronics and Communication Engineering \\ National Institute of Technology Warangal \\ Warangal, India \\ sarma@nitw.ac.in
}

\begin{abstract}
A compact single probe feed asymmetrical semicircular fractal boundary patch antenna based on HIS (high impedance surface) is proposed for wide bandwidth at Wi-Fi band. Circular polarization operation can be obtained by embedding semi-circle fractal curves along the edges of the square patch antenna. The 10-dB return loss bandwidth is $15.13 \%(2.32 \mathrm{GHz}-2.70 \mathrm{GHz})$. The 3-dB axial ratio bandwidth is $4.11 \%(2.38 \mathrm{GHz}-2.48 \mathrm{GHz})$. The close relationship between simulation results and measured results establishes the antenna usefulness.
\end{abstract}

Keywords-high impedance surface; circular polarization; semi circular fractal

\section{INTRODUCTION}

A microstrip patch antenna (being compact, low profile, easy to manufacture and multifunctioning) is the most coveted candidate for modern day wireless communication applications. Wideband antennas with circular polarization operation are mostly used in handheld device applications. Orientation mismatch between receiver and transmitter can be avoided by using circularly polarized (CP) antennas. CP antennas are widely used in WLAN, Wi-Fi and WiMAX applications. Metamaterials are a good choice in designing novel antennas like compact wide band antennas because of their artificial electromagnetic properties [1-10, 12]. Metamaterials are classified into single negative materials (SNG) $[1,2,9,11]$, double negative materials (DNG) [5-8], electromagnetic band gap materials (EBG) $[13,14]$ and chiral materials. EBGs are divided into mushroom EBG structures and VIA less EBG structures. Fractals are the self-repetitive curves used to design compact antennas [15]. A compact microstrip antenna with dual-band operation having both unidirectional linear polarization and omni directional circular polarization properties based on epsilon negative materials is designed in [11]. Dual band patch antenna with unidirectional circular Polarization (CP) and omni directional $\mathrm{CP}$ based on EBG is designed in [14]. In this paper, a compact microstrip patch antenna on HIS with semi-circle fractal curves is designed and simulated in single frequency with good 10-dB return loss bandwidth and $3-\mathrm{dB}$ axial ratio bandwidth. The impedance bandwidth of the proposed antenna is $15.13 \%$ $(2.32 \mathrm{GHz}-2.70 \mathrm{GHz})$. The $3-\mathrm{dB}$ axial ratio bandwidth is $4.11 \%$
(2.38GHz-2.48GHz). Ansoft HFSS (high frequency structure simulator) software tool was used to simulate the antenna.

\section{ANTENNA GEOMETRY}

The semi-circle fractal boundary patch antenna geometry is shown in Figure 1 which is also printed on Rogers RT/Duroid with dielectric constant 2.2. The presented antenna has two substrates (bottom and top), on the top substrate the recommended antenna is designed and on the bottom substrate the HIS with a planar array of $3 \times 3$ fractal mushroom unit cells is printed. The circular polarization (CP) operation can be obtained by inserting semi-circle curves with IF's Rx and Ry along $\mathrm{x}$ and $\mathrm{y}$ axes respectively. The $10-\mathrm{dB}$ return loss bandwidth and axial ratio bandwidth can be improved by optimizing IF along each edge of the antenna. The optimized dimensions of the proposed antenna are given in Table I.

TABLE I. PARAMETER VALUES

\begin{tabular}{|c|c|}
\hline Parameter & Value in mm \\
\hline $\mathrm{L} 1$ & 38 \\
\hline $\mathrm{L} 2$ & 30 \\
\hline $\mathrm{a} 1$ & 8 \\
\hline $\mathrm{a} 2$ & 13 \\
\hline $\mathrm{h} 1$ & 1.6 \\
\hline $\mathrm{h} 2$ & 1.6 \\
\hline $\mathrm{Rx} 1=\mathrm{Rx} 2=\mathrm{Rx}$ & 2 \\
\hline $\mathrm{Ry} 1=\mathrm{Ry} 2=\mathrm{Ry}$ & 5 \\
\hline
\end{tabular}

\section{SEMI-CIRCLE FRACTAL CURVES AND SIMULATION RESULTS}

Equal indentation radii $(\mathrm{Rx} 1=\mathrm{R} \times 2=\mathrm{Ry} 1=\mathrm{Ry} 2)$ along the four sides of the square patch antenna result in linear polarization. Circular polarization radiation can be obtained by loading different indentation radii along each side of the patch $(\mathrm{Rx} 1 \neq \mathrm{R} x 2 \neq \mathrm{Ry} 1 \neq \mathrm{Ry} 2) \quad$ or $(\mathrm{Rx} 1=\mathrm{Rx} 2=\mathrm{Rx} \neq \mathrm{Ry} 1=\mathrm{Ry} 2=\mathrm{Ry}) \quad$ or $(\mathrm{Rx} 1 \neq \mathrm{R} x 2 \neq \mathrm{Ry} 1 \neq \mathrm{R} y 2)$. High bandwidth can be obtained when the indentation radii along the same axis are equal and at the same time are not equal along the perpendicular axis $(\mathrm{Rx} 1=\mathrm{R} x 2=\mathrm{R} x \neq \mathrm{Ry} 1=\mathrm{Ry} 2=\mathrm{Ry})$. Operation of the proposed antenna can be understood by considering an evolution of patch antenna design shown in Figure 2. Square patch Ant1 on single substrate is chosen as reference which is resonating at $3.05 \mathrm{GHz}$ 
with linear polarization. The semi-circle fractal curves with different indentation radii are inserted into Ant1 to get antennas Ant 2 to Ant11, which results in single band of operation with less $10-\mathrm{dB}$ return loss bandwidth and axial ratio bandwidth. The 10-dB return loss characteristics of all simulated antennas on single substrate are shown in Figure 3. The impedance bandwidth of each antenna is listed in Table II.

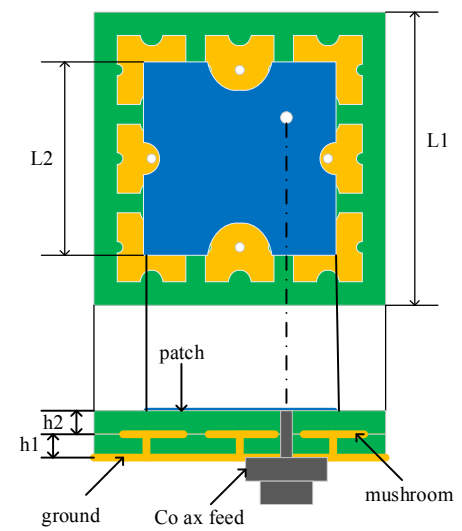

(a)

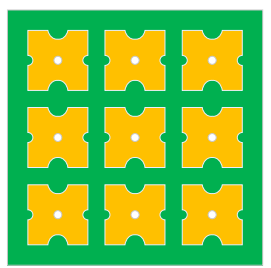

(b)

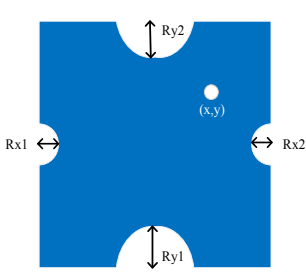

(c)
Fig. 1. (a) Geometry of the proposed antenna (b) top view of the HIS (c) top view of the patch

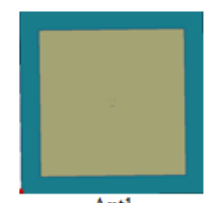

Ant1

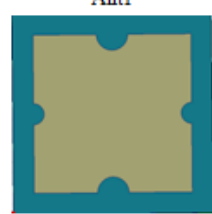

Ant4

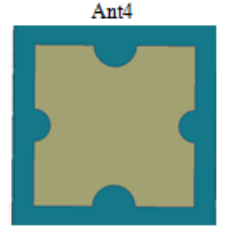

Ant7

Ant10

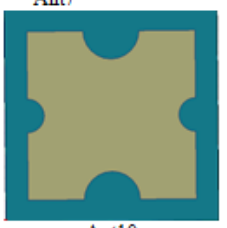

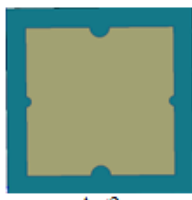

Ant2

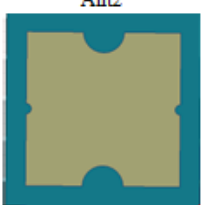

Ant5

Ant8

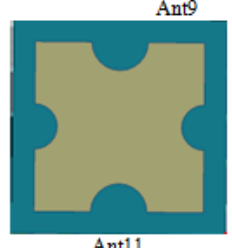

Ant11

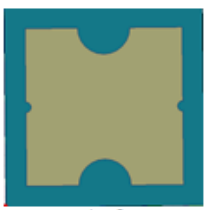

Fig. 2. Evaluation of the proposed antenna on single substrate

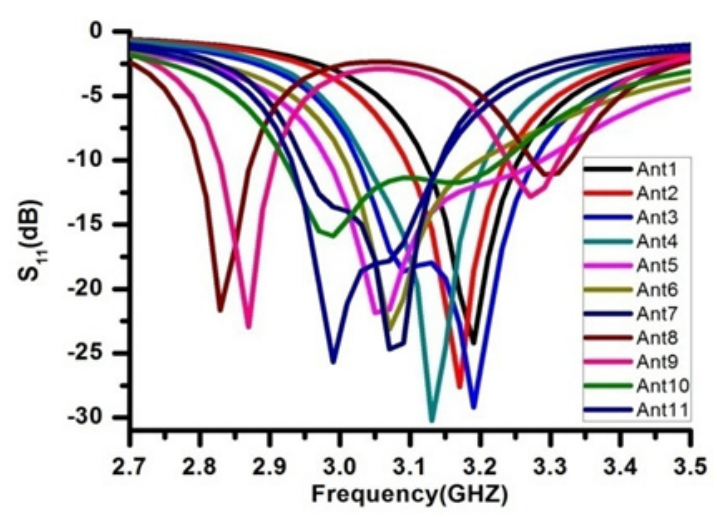

Fig. 3. Simulated return loss characteristics of antennas Ant1 -Ant11

TABLE II. IMPEDANCE BANDWITH OF EACH ANTENNA

\begin{tabular}{|c|c|c|c|}
\hline \multirow{2}{*}{ Antenna } & \multicolumn{2}{|c|}{ IRs (in mm) } & \multirow{2}{*}{ Impedance Bandwidth } \\
\cline { 2 - 3 } & Rx & Ry & \\
\hline Ant1 & -- & -- & $(3.13-3.25) 3.76 \%$ \\
\hline Ant2 & 1 & 2 & $(3.11-3.23) 3.78 \%$ \\
\hline Ant3 & 1 & 3 & $(3.03-3.27) 7.61 \%$ \\
\hline Ant4 & 2 & 3 & $(3.05-3.19) 4.56 \%$ \\
\hline Ant5 & 1 & 4 & $(2.98-3.27) 9.29 \%$ \\
\hline Ant6 & 2 & 4 & $(3.01-3.19) 5.80 \%$ \\
\hline Ant7 & 3 & 4 & $(2.94-3.13) 6.27 \%$ \\
\hline Ant8 & 1 & 5 & $(2.80-2.86) 2.12 \%$ \\
\hline Ant9 & 2 & 5 & $(2.82-2.88) 2.10 \%$ \\
\hline Ant10 & 3 & 5 & $(2.92-3.23) 10.26 \%$ \\
\hline Ant11 & 4 & 5 & $(2.94-3.13) 6.27 \%$ \\
\hline
\end{tabular}

To get widened impedance bandwidth with circular polarization at $\mathrm{Wi}-\mathrm{Fi}$ band the same antenna is implemented on HIS (Figure 4). HIS is made of planar array of $3 \times 3$ fractal mushroom unit cells. Each unit cell has $8 \times 8 \mathrm{~mm}^{2}$ square patch and $0.5 \mathrm{~mm}$ radius VIA where all unit cells connected to ground through VIAs. The semi-circle fractal curves are inserted into each square mushroom unit cell to make required HIS. Finally Ant20 is the proposed antenna with good wide bandwidth. The $10-\mathrm{dB}$ return loss characteristics of all simulated antennas on fractal mushroom HIS are shown in Figure 5 and the impedance bandwidth of each antenna is listed in Table III. The simulated current distribution of the proposed antenna at $2.4 \mathrm{GHz}$ is shown in Figure 6 . The simulated radiation efficiency of the proposed antenna is shown in Figure 7. The efficiency is good at $2.4 \mathrm{GHz}(98 \%)$.

TABLE III. IMPEDANCE BANDWITH OF EACH ANTENNA

\begin{tabular}{|c|c|c|c|}
\hline \multirow{2}{*}{ Antenna } & \multicolumn{2}{|c|}{ IRs (in mm) } & \multirow{2}{*}{ Impedance Bandwidth } \\
\cline { 2 - 3 } & Rx & Ry & \\
\hline Ant12 & -- & -- & $(2.40-2.56) 6.45 \%$ \\
\hline Ant13 & 1 & 2 & $(2.42-2.56) 5.60 \%$ \\
\hline Ant14 & 1 & 3 & $(2.40-2.58) 7.22 \%$ \\
\hline Ant15 & 2 & 3 & $(2.42-2.58) 6.45 \%$ \\
\hline Ant16 & 1 & 4 & $(2.30-2.58) 11.47 \%$ \\
\hline Ant17 & 2 & 4 & $(2.34-2.56) 8.90 \%$ \\
\hline Ant18 & 3 & 4 & $(2.40-2.56) 6.45 \%$ \\
\hline Ant19 & 1 & 5 & $(2.28-2.70) 16.86 \%$ \\
\hline Ant20 & 2 & 5 & $(2.32-2.70) 15.13 \%$ \\
\hline Ant21 & 3 & 5 & $(2.30-2.60) 12.24 \%$ \\
\hline Ant22 & 4 & 5 & $(2.36-2.54) 7.34 \%$ \\
\hline
\end{tabular}




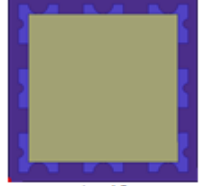

Ant12

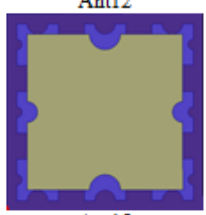

Ant15

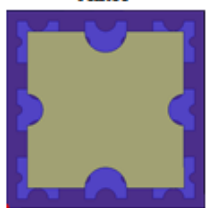

Ant18

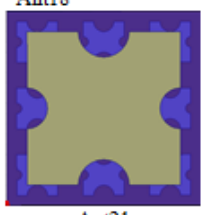

Ant21

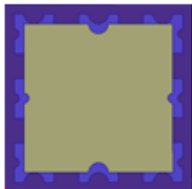

Ant13

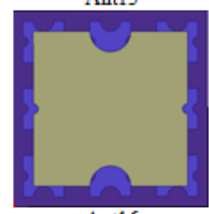

Ant16

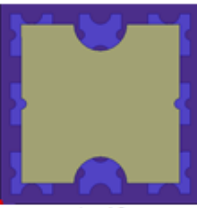

Ant19

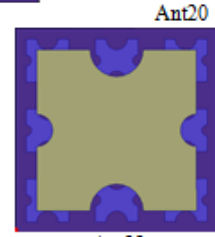

Fig. 4. Evaluation of the proposed antenna on HIS

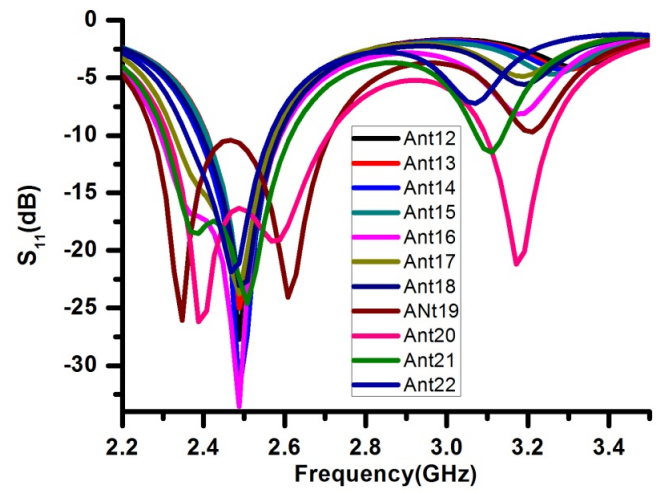

Fig. 5. Return loss characteristics of HIS antennas

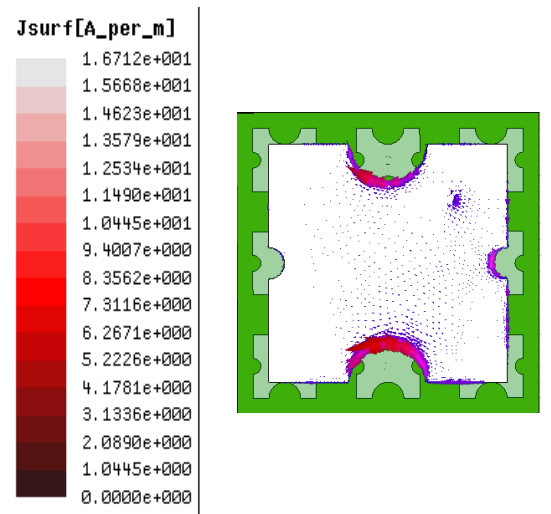

Fig. 6. Simulated current distribution of proposed antenna at $2.4 \mathrm{GHz}$

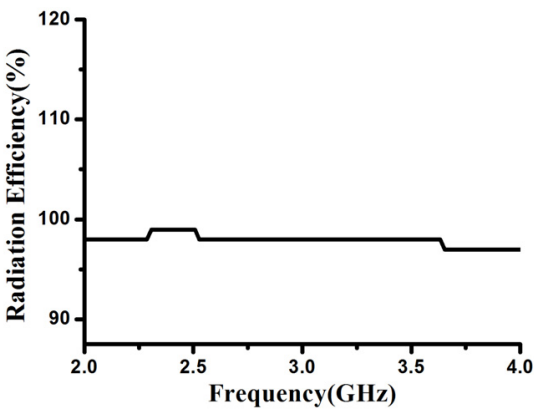

Fig. 7. Radiation efficiency of the proposed antenna

\section{MEASURED RESULTS AND DISCUSSION}

The proposed antenna (Ant20) is fabricated on Rogers RT/Duroid substrate (Figure 8). Fractal mushroom HIS and fractal patch antenna are individually fabricated. HIS is printed on bottom substrate and the patch antenna is placed on top substrate without ground. The VIAs are fabricated with the help of through hole copper plating technique. Both substrates are attached with the help of paper tape. The dimensions of both substrates are $38 \times 38 \times 1.6 \mathrm{~mm}^{3}$. The return loss characteristics are measured using Agilent 8719A microwave network analyzer. Radiation pattern measurements are taken in an anechoic chamber having physical dimensions $22.5 \times 12.5 \times 11.5 \mathrm{~m}^{3}$. The operating frequency range of the anechoic chamber is $400 \mathrm{MHz}$ to $18 \mathrm{GHz}$. The input power given to transmitter is $-40 \mathrm{dBm}$.

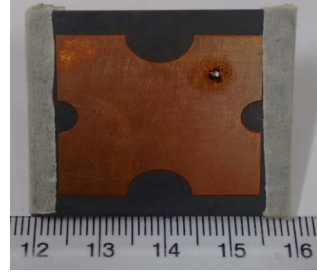

(a)

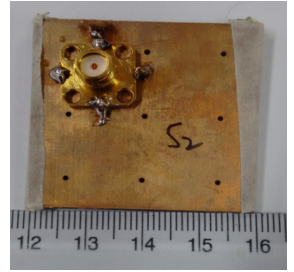

(b)
Fig. 8. Photos of fabricated Ant20: (a) top view (b) bottom view

The measured return loss characteristics along with simulated data are given in Figure 9. Measured results are in close agreement with simulated results. The discontinuity at patch mode band indicates possibility of circular polarization radiation. The axial ratio characteristics are given in Figure 10. While the impedance bandwidth is $15.13 \%(2.32 \mathrm{GHz}-$ $2.70 \mathrm{GHz}), 3-\mathrm{dB}$ axial ratio bandwidth is $4.11 \%(2.38 \mathrm{GHz}-$ $2.48 \mathrm{GHz}$ ). The minimum axial ratio value of $0.5 \mathrm{~dB}$ occurred at the center frequency. The radiation patterns of the proposed antenna are depicted in Figure 11. The measured and simulated gains are given in Figure 12.

\section{CONCLUSION}

A compact single probe feed semi-circle fractal boundary microstrip patch antenna based on fractal mushroom HIS is proposed and studied experimentally for wide impedance and axial ratio bandwidths. The $10-\mathrm{dB}$ return loss bandwidth is 
$15.13 \%$. The $3-\mathrm{dB}$ axial ratio bandwidth is $4.11 \%$. The proposed antenna covers WLAN $(2.4 \mathrm{GHz})$ band.

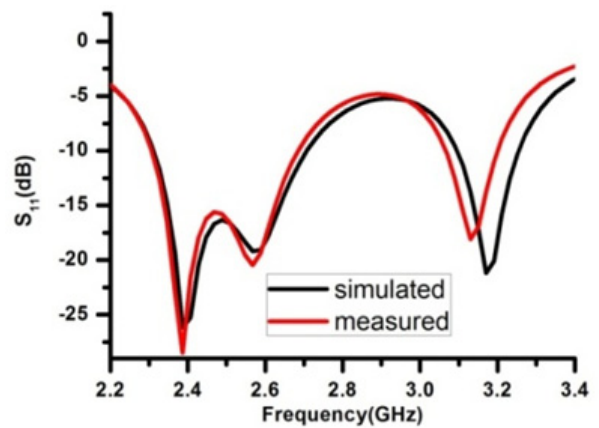

Fig. 9. Simulated and measured return loss characteristics of Ant20

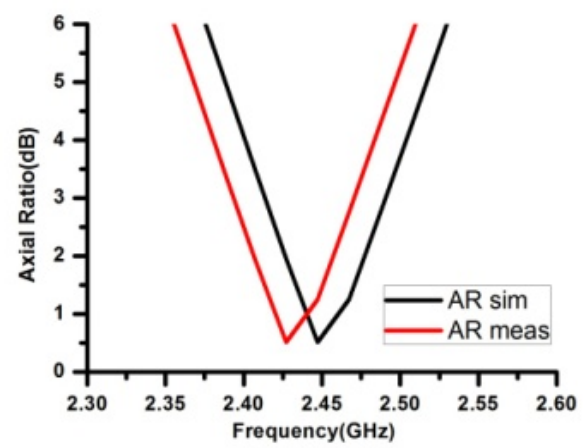

Fig. 10. Simulated and measured axial ratio characteristics of Ant20

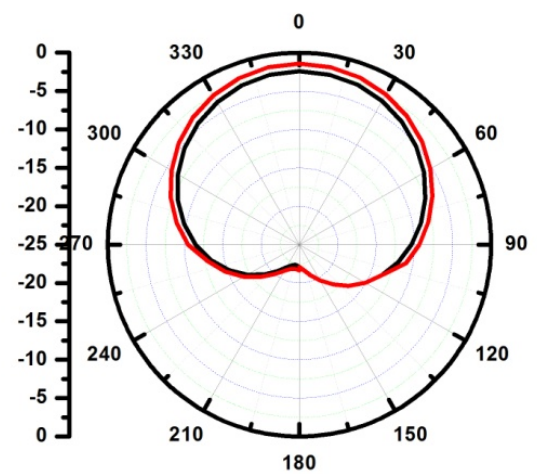

(a)

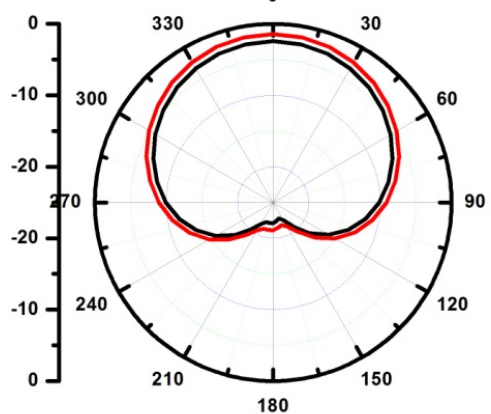

(b)

Fig. 11. Simulated and measured radiation patterns at $2.4 \mathrm{GHz}$ (a) E Plane (b) H Plane

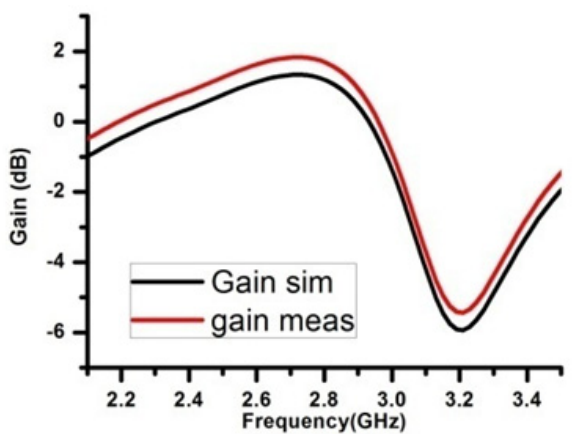

Fig. 12. Simulated and measured gain of the proposed antenna

\section{REFERENCES}

[1] G. V. Eleftheriades, K. G. Balmain, Negative-refraction metamaterials: fundamental principles and applications, John Wiley \& Sons, 2005

[2] C. Caloz, T. Itoh, Electromagnetic metamaterials: transmission line theory and microwave applications, John Wiley \& Sons, 2005

[3] A. Sanada, M. Kimura, I. Awai, C. Caloz, T. Itoh, "A planar zerothorder resonator antenna using a left-handed transmission line", 34th European Microwave Conference, Amsterdam, Netherlands, October 12-14, 2004

[4] D. Sievenpiper, L. Zhang, R .F. J. Broas, N. G. Alexopolous, E. Yablonovitch, "High-impedance electromagnetic surfaces with a forbidden frequency band", IEEE Transactions on Microwave Theory and Techniques, Vol. 47, No. 11, pp. 2059-2074, 1999

[5] A. Lai, T. Itoh, C. Caloz, "Composite right/left-handed transmission line metamaterials", IEEE Microwave Magazine, Vol. 5, No. 3, pp. 34-50, 2004

[6] C. J. Lee, K. M. K. H. Leong, T. Itoh, "Composite right/left-handed transmission line based compact resonant antennas for RF module integration", IEEE Transactions on Antennas and Propagation, Vol. 54, No. 8, pp. 2283-2291, 2006

[7] Y. Dong, H. Toyao, T. Itoh, "Compact circularly-polarized patch antenna loaded with metamaterial structures", IEEE Transactions on Antennas and Propagation, Vol. 59, No. 11, pp. 4329-4333, 2011

[8] K. Saurav, D. Sarkar, K. V. Srivastava, "Dual-polarized dual-band patch antenna loaded with modified mushroom unit cell", IEEE Antennas and Wireless Propagation Letters, Vol. 13, pp.1357-1360, 2014

[9] J. H. Park, Y. H. Ryu, J. G. Lee, J. H. Lee, "Epsilon negative zerothorder resonator antenna", IEEE Transactions on Antennas and Propagation, Vol. 55, No. 12, pp. 3710-3712, 2007

[10] H. Tang, X. Zhao, "Center-fed circular Epsilon-negative zeroth-order resonator antenna", Microwave and Optical Technology Letters, Vol. 51, No.10, pp. 2423-2428, 2009

[11] W. Q. Cao, "Compact dual-band dual-mode circular patch antenna with broadband unidirectional linearly polarised and omnidirectional circularly polarised characteristics", IET Microwaves, Antennas \& Propagation, Vol. 10, No. 2, pp. 223-229, 2016

[12] W. Q. Cao, A. J. Liu, B. N. Zhang, T. B. Yu, D. S. Guo, Y. Wei, Z. P. Qian, "Multi-band multi-mode microstrip circular patch antenna loaded with metamaterial structures", Journal of Electromagnetic Waves and Applications, Vol. 26, No. 7, pp. 923-931, 2012

[13] W. Q. Cao, A. Liu, B. Zhang, T. Yu, Z. Qian, "Dual-Band Spiral PatchSlot Antenna With Omnidirectional CP and Unidirectional CP Properties", IEEE Transactions on Antennas and Propagation, Vol. 61, No. 4, pp. 2286-2289, 2013

[14] J. Kamiya, K. Shirota, T. Yagi, T.Nakazawa, "Study of EBG Structures using Metamaterial Technology", OKI Technical Review, No. 219, pp. $1-4,2012$

[15] V. V. Reddy, N. V. S. N. Sarma, "Compact circularly polarized asymmetrical fractal boundary microstrip antenna for wireless applications", IEEE Antennas and Wireless Propagation Letters, Vol. 13, pp. 118-121, 2014 